\title{
The Global Challenge of Inequality
}

\author{
José Antonio Ocampo
}

\begin{abstract}
1 Introduction
Let me start by congratulating IDS on its fortieth anniversary. Over the past four decades, the Institute has become an essential foundation for and major contributor to development debates. I am therefore both happy and proud to have been invited to participate in this special event and to offer my reflections as a senior economist at the United Nations.
\end{abstract}

The current world economic system exhibits many positive features. It is certainly a dynamic system, with great capacity to innovate and great flexibility to adapt to changing circumstances. And it is a competitive system that is enabling many producers in developing countries to get a foothold in global markets. Yet, as we well know, the world economic system also faces major challenges. Some of the most recognised are those associated with environmental degradation - not only climate change but also the rapid loss of biodiversity and the deterioration in the quality of air and water. In recent economic debates, the challenge of maintaining macroeconomic stability in the global economic system has also been emphasised. It means reckoning with the large global imbalances and with the rapid rise of unregulated financial activities which together generate the risk of large global financial disturbances.

Despite the crucial importance of these two challenges, I want to concentrate my attention in these remarks on a third: the uneven distribution of the benefits of economic growth. This involves two quite different dimensions: the uneven distribution of income among countries and the uneven distribution of income within countries.

\section{Growing inequalities}

The international income inequality gap involves longstanding and still growing North-South

disparities. This gap has been widening over the past two centuries, with only brief interruptions, including during the last three years of booming world economic growth. If we exempt this recent period, we see a significant rise in inequality between developed and developing countries since the 1980s; particularly a sharp rise in the gap between the extremes, between high-income and low-income countries. The most troubling pattern, which is largely responsible for this widening inequality over the past 25 years, has been the large number of growth collapses in many parts of the developing world: sub-Saharan Africa, the Middle East, Latin America and the Caribbean, and Central and Eastern Europe.

We have also seen important changes within the North and South groupings. In the industrialised world, the USA has again become the leading economy in terms of economic growth - in sharp contrast with the pattern observed during the postwar 'golden age' between 1950 and 1973. Meanwhile, slow economic growth in most parts of the developing world has been accompanied by booms in South Asia and, particularly, in East Asia.

The second dimension - growing inequality of income distribution within countries - is much more broad-based. According to research undertaken by the United Nations University's World Institute for Development Economic Research, 48 out of 73 countries for which such information is available experienced a deterioration of income distribution during the past three decades, and most of them in a substantial way, including major economies such as China, Russia and the USA. And those 48 countries contain 87.5 per cent of the population of the sample countries. Only nine countries, representing 2.7 per cent of the sample population, experienced a clear improvement in income distribution. In the rest, income distribution remained essentially unchanged.

What these numbers mean is that approximately nine out of ten of the world's citizens live in countries 
where income distribution has deteriorated. This is a staggering figure. But we have not yet recognised this inequality for what it is: a truly global pandemic.

\section{Asymmetries in the international economic system}

A simple way to understand the forces that underlie international inequalities is to look at the three basic asymmetries of the current international economic system.

The first is the greater macroeconomic vulnerability of developing countries to external shocks. This vulnerability has tended to increase with the tighter integration of the world economy, and its nature has also been changing. While the transmission of external shocks through trade remains important, financial shocks have come to play a more prominent role, revisiting past patterns, such as the financial boom-and-bust cycle of the 1920s and 1930s.

In this sense, macroeconomic asymmetries derive both from the fact that the currencies of industrial countries serve as the international currencies and that, although all capital markets are pro-cyclical, capital flows to developing countries are particularly volatile. Moreover, whereas macroeconomic policy in developed countries tends to be counter-cyclical and can thus smooth out the effects of pro-cyclical financial markets, pro-cyclical macroeconomic policies in developing countries tend to reinforce the capital account and trade cycles. That is, developing countries lack the room for manoeuvre to adopt counter-cyclical macroeconomic policies. At the same time, market players expect this and evaluate authorities in the developing world on their ability to adopt such pro-cyclical stances.

The second asymmetry derives from the high concentration of technical progress in the developed countries. The diffusion of technical progress from the source countries to the rest of the world remains 'relatively slow and uneven', according to Raúl Prebisch's classical predicament. This reflects, among other factors, the prohibitive costs of entry into the more dynamic technological activities and the rising costs of technology transfers due to the generalisation and strengthening of intellectual property rights. The combined effect of these factors explains why, at the global level, the productive structure has exhibited a high and persistent concentration of technical progress in the industrialised countries, which thus maintain their dominant position in the most dynamic sectors of international trade and their hegemony in the establishment of large transnational enterprises.

The third asymmetry is associated with the contrast between the high mobility of capital and the restrictions on the international movement of labour, particularly of unskilled labour. This asymmetry is characteristic of the present phase of globalisation, as it was not manifested in the nineteenth and early twentieth centuries (a period characterised by large mobility of both capital and labour) or in the first 25 years following the Second World War (a period in which both factors exhibited little mobility). As Dani Rodrik emphasised, asymmetries in the international mobility of the factors of production generate biases in the distribution of income in favour of the more mobile factors (capital and skilled labour) and against the less mobile factors (less skilled labour). They also affect relations between developed and developing countries, in as much as the latter have a relative abundance of less skilled labour.

\section{Overcoming global asymmetries}

Since the creation of the United Nations Conference on Trade and Development (UNCTAD) in the early 1960s, the need to correct the asymmetries that continue to characterise the international economic system has been explicitly recognised. The commitments concerning the flow of Official Development Assistance (ODA) and 'special and differential treatment' for developing countries in trade issues were some of the partial although relatively frustrating results of this effort to build a 'new international economic order'. This vision has eroded dramatically in recent decades and has been supplanted by an alternative paradigm, according to which the basic objective of the international economic system should be to ensure a uniform set of rules - a 'level playing field'- leading to the efficient functioning of market forces.

It is important to underline that, contrary to this trend, new principles were agreed in the area of sustainable development at the outset of the 1990s, notably Principle 7 of the Earth Summit of Rio de Janeiro in 1992, which focused on the 'common but differentiated responsibilities' of developed and developing countries.

In the new vision of the international economic system stressing the need for a level playing field, the 
essential gains for developing countries lie in the eventual dismantling of protection of 'sensitive' sectors in industrialised countries, in the guarantees that export sectors derive from an international trading system with clear and stable rules, and in the design of preventive macroeconomic policies that serve as 'self-protection' against international financial volatility. The correction of international asymmetries is recognised only in relation to the provision of ODA to the least developed countries.

Even though all these gains would be desirable, could they be sufficient in themselves to generate a greater convergence in levels of development? Given the strength of existing asymmetries, the answer is probably no. In certain situations, taking the envisioned measures could even aggravate existing inequalities. Moreover, as Ha-Joon Chang, among others, has emphasised, levelling the playing field, the norm that has guided efforts to reform the international economic system in recent decades, implies restrictions on developing countries that the industrialised countries themselves never faced in previous periods of their history: standards of intellectual property protection originating from the industrialised countries that generate technology and limitations on policy options for promoting new production sectors for either domestic or external markets. Thus, the concept of 'common but differentiated responsibilities', the already classic principle of 'special and differential treatment', and the need to maintain 'policy space' for developing countries, may be more appropriate guidelines for building a more equitable global order.

These considerations point to the essential elements that should guide international economic reform vis$\dot{a}$-vis the developing countries. The first of the asymmetries suggests that the basic function of the international financial institutions, from the perspective of the developing countries, is to compensate for the pro-cyclical impact of financial markets, smoothing financial boom-and-bust at its source through adequate regulation, and providing a larger degree of freedom for countries to adopt counter-cyclical macroeconomic policies. This implies, in turn, adequate surveillance during boom periods in order to avoid accumulating excessive macroeconomic and financial risks, and adequate financing during crises in order to smooth the required adjustment in the face of 'sudden stops' of external financing. An additional and equally essential function is to act as a countervailing force to the concentration of credit in private capital markets, making resources available to countries and economic agents that have limited access to credit in international capital markets.

The second asymmetry suggests that the multilateral trade system must facilitate the smooth transfer to developing countries of the production of primary commodities, technologically mature manufacturing activities and standardised services. It should, therefore, avoid erecting obstacles to such transfers through protection or subsidies. Moreover, this system must also accelerate developing countries' access to technology and ensure their increasing participation in the generation of technology and in the production of goods and services with high technological content.

In light of the problems that developing countries face in ensuring a dynamic transformation of their productive structures, a 'special and differential treatment' is required, particularly in two critical areas: (1) regimes for intellectual property protection that avoid creating excessive costs for developing countries and limiting the modalities through which the transfer can be made; and (2) instruments to promote new exports ('infant export industries'), which foster diversification and increase their valueadded. All this clearly requires maintaining the 'policy space' to adopt active industrial (and, more generally, production sector) policies, as well as a search for appropriate instruments in order to avoid a sterile competition among countries to attract footloose industries.

Lastly, to overcome the third asymmetry, labour migration must be fully included in the international agenda, at the global and the regional levels, and development concerns must be mainstreamed in the migration policies of both countries of origin and destination. Moreover, international agreements must envisage complementary mechanisms to facilitate migration, such as the recognition of educational, professional, and labour credentials, the transferability of social security benefits, and the facilitation and reduction of costs of transferring remittances.

\section{Facing domestic inequalities}

Despite its potential to manage international inequalities, the international system does not have a clear capacity to help address income distribution 
within countries. Social policy and the management of social cohesion have been and will continue to be the domain of nation states - at least in the foreseeable future. Given that scenario, what we could certainly do at the international level is seek to ensure that international rules do not constrain the space for social policy or social cohesion within any country, whether industrialised or developing.

At the national level, placing the need to redress inequalities at the centre of economic and social policies requires, first, active and consistent human development efforts, supported by adequate fiscal resources. The experiences of developing countries show that major advances in human development can be achieved, even at relatively low levels of income. The same is true of the allocation of fiscal resources to social spending. For example, in Latin America, some countries assign only 6 per cent of gross domestic product (GDP) to social spending, while others allocate over 20 per cent. Thus, the allocation of adequate amounts of fiscal resources to social spending is, in a significant sense, a policy choice. Yet, for low-income countries, this requires consistent provision of ODA, and thus the meeting by all industrial countries of the United Nations target of 0.7 per cent of the gross national income (GNI) in ODA. Other international factors may also be crucial. It is important, in particular, to reflect on whether the adequate allocation of government revenues for social spending has become increasingly constrained by the world competition to reduce taxation of capital income.

Nonetheless, progress in human development, while essential in itself and necessary to guarantee access to economic opportunities, cannot alone bring social progress. Equally, and perhaps even more challenging, is to guarantee that economic growth is inclusive. The 'inclusiveness' of economic growth is certainly not an automatic outcome of market forces and must be ensured through explicit public choices. These choices involve at least three dimensions.

First, is placing employment at the centre of economic policy, including the actions of independent central banks. The capacity of economic growth to generate decent and productive employment, especially for the poorest, is just as important as growth itself. Employment generation is, in fact, the key link between economic and social progress. Unfortunately, we are seeing, in every region of the world, inadequate generation of quality employment, even in developing countries experiencing rapid economic growth. And the growing under-utilisation of labour has exacerbated productivity gaps between different economic agents in developing countries, particularly between workers engaged in formal economic activities and those engaged in informal ones.

Second, is to address the growing vulnerability to risks faced by workers and, more generally, by the poor, including: the insecurity in incomes and jobs generated by more competitive environments, the more volatile economic growth environment experienced by many developing countries, the underdevelopment of social protection systems in most developing countries, and the difficulties experienced by many social security systems in middle- and high-income countries, which has led to the privatisation of risks. This means moving beyond the narrow conception of social protection systems as compensatory mechanisms for adverse social effects generated by economic processes - that is, as mere 'social safety nets'. It requires integrated economic and social policies that aim at preventing crises and developing permanent social protection systems, based on the principles of solidarity and universal coverage, and that manage basic risks in an integrated way, particularly nutrition, health, disability, ageing and unemployment. It will, admittedly, take longer to develop such systems in countries where the labour force is largely rural or informal, but this should be the ultimate objective of efforts in this area.

The third dimension, is placing the issue of growing income and wealth inequalities at the centre of economic policies. A comparison of income inequality among industrialised countries shows that those with a better distribution of income also have a more developed social welfare state. But this means confronting the growing share of capital income that characterises the world economy today and the bias in demand for labour towards high skills, which has led to a worsening distribution of labour income between skilled and unskilled workers. Progressive income taxation is essential for this task, but is an instrument that seems to be under increasing stress in the current global environment. Perhaps we need even more ambitious policies on that front. And helping the poor and even the middle classes to build assets should be a priority of economic policies. This includes access to housing and the development of 
productive assets, which will be critical for the development of small and medium enterprises. As we well know, these firms and productive selfemployment are major mechanisms for job creation worldwide.

Cutting across these three dimensions of public choice is the essential need to develop a genuinely integrated approach to economic and social development. This will in turn require not only a change in outlook, but new institutions to support the development of integrated policy frameworks. At the national level, these integrated frameworks ought to start by designing rules to ensure the 'visibility' of the social effects of economic policies and by asking macroeconomic authorities (including independent central banks) regularly to examine the effects of policies on the main social variables, particularly employment and incomes of workers. Similarly, finance ministers should be asked to include analysis of likely distributive effects in any budgetary or tax reform initiative presented to their legislatures. And public entities entrusted with technological, industrial, or agricultural policies ought regularly to evaluate the distributional consequences of their programmes. The integrated frameworks should ultimately be developed into efficient coordination systems between economic

\section{Note}

* The opinions presented here are those of the author and do not reflect any official position of the United Nations. and social authorities, in which social objectives are effectively mainstreamed into economic policy decision-making - that is, into monetary, fiscal, trade, production, and technology policies.

\section{Implications for development research}

We were asked to reflect in the IDS40 conference on the implications of our views for development research. Let me underscore three, which are also relevant for development cooperation. The first is that the fight against inequality, both international and domestic, should be brought to the centre of international cooperation and rule-making and to the centre of development policies. The second is that focusing on domestic governance and policies in developing countries, the central focus of attention of orthodox development thinking over the past decades, and the focus of development cooperation today, is likely to be insufficient. It is equally important to think about rules that allow the benefits of global trade, investment and finance to spread among all members of the international economy. The third is that such rules should maintain 'policy space' for developing countries to pursue their development strategies and, crucially, to guarantee that development is pursued with a strong equity dimension. 